\title{
An Analysis of Digital Inclusion Projects: Three Crucial Factors and Four Key Components
}

\author{
Chris Smith \\ Boise State University, Boise, Idaho, United States
}

\section{Chrissmith12@u.boisestate.edu}

\begin{abstract}
This paper provides an in-depth analysis into two case studies aimed at addressing the digital divide in two developing countries. A detailed description is provided for each case study along with an analysis of how successful the two projects were at addressing the digital divide in Siyabuswa, South Africa and Ennis, Ireland. The two case studies were both community-based ICT projects in rural areas of their respective countries. However, citizens in Siyabuswa had to continuously work hard to obtain new resources for a central hub which serviced the entire community, while citizens in Ennis were awarded a grant with an abundance of ICT technology including an Internet connection in every home. A conceptual framework for analyzing the success of digital inclusion projects was developed through a comprehensive literature review. This paper will identify the three factors (value, sustainability, and scalability) and four key components (digital equity, excellence, opportunity, and empowerment) that make up the framework, analyze each of the two case studies based on the framework, and explore future implications for addressing gaps in ICT access through the implementation of digital inclusion projects.
\end{abstract}

Keywords: digital inclusion projects, digital divide, digital empowerment, scalability, Information Age Town, Siyabuswa Educational Improvement and Development Trust Project.

\section{Introduction}

Varying levels of access to information and communication technologies (ICT) between developed and developing countries have created what is known as the digital divide (Wresch, 2009). According to Costello (2000), access to information and the use of the Internet are essential components of learning, training, and business development in developing countries that should not be limited by geographic location. Providing access to ICT sounds simple enough; however the process involves complex social, political, institutional, and cultural implications related to ICT access and people's ability to use ICT effectively (Warschauer, 2004). Over the past two decades, a number of attempts have been made to address the digital divide, including the introduction of

Material published as part of this publication, either on-line or in print, is copyrighted by the Informing Science Institute. Permission to make digital or paper copy of part or all of these works for personal or classroom use is granted without fee provided that the copies are not made or distributed for profit or commercial advantage AND that copies 1) bear this notice in full and 2) give the full citation on the first page. It is permissible to abstract these works so long as credit is given. To copy in all other cases or to republish or to post on a server or to redistribute to lists requires specific permission and payment of a fee. Contact Publisher@InformingScience.org to request redistribution permission.
Minimally Invasive Education projects such as the "hole in the wall" (Mitra et al., 2005) and Diffusion of Innovation projects like One Laptop Per Child (OLPC) (Kraemer, Dedrick \& Sharma, 2009). Minimally Invasive Education projects (MIEs) involve more studentcentered learning based on interacting with the surrounding environment (Dangwal \& Kapur, 2009), while the Diffusion of Innovation projects focus 
on the rate of adoption according to relative advantage, compatibility, complexity, testability, and observability (Kraemer et al., 2009). In addition to MIEs and DIs, one initiative that has seen a great deal of success involves what are known as digital inclusion projects (DIPs) (Madon, Reinhard, Roode, \& Walsham, 2009). The mission of these projects has been to address technology access and the efficient use of ICTs among citizens who have been left behind due to discrepancies in education level, age, gender, or geographic location through improved planning and delivery (Alamelu, 2013). Aimed at improving social inclusion, DIPs also provide support for learning and building capacity while improving ICT access among targeted groups (Trauth, Howcroft, Butler, Fitzgerald, \& DeGross, 2006). An analysis of the research detailing successful examples from past DIPs revealed three crucial factors and four key components that have been used to evaluate project outcomes. This paper will analyze two case studies based on the three crucial factors and four key components for implementing successful DIPs, and explore future implications for addressing gaps in ICT access through an analysis of two unique digital inclusion projects.

\section{Three Crucial Factors and Four Key Components}

In a similar analysis of three digital inclusion project case studies, Madon et al. (2009) identified three crucial factors that must be considered when planning DIPs, which include determining the value, sustainability and scalability of the project. Measuring the value of a DIP involves more than simply identifying possible monetary implications. It also includes predicting how the implementation of the project will affect the entire community or culture. At the same time, understanding sustainability of a DIP involves a financial analysis to predict if or how the initiative will continue once the initial funding source has been exhausted (Harris, Kumar, \& Balaji, 2003). Finally, identifying the level of scalability for the DIP determines the level at which the size and scope of the project can be expanded or transferred from one setting to another (Sahay \& Walsham, 2006).

Madon et al. (2009) further expanded on the concept of the three crucial factors by identifying four key processes of institutionalism which are interwoven within digital inclusion projects. The four key processes involved gaining acceptance by the participating community, stimulating communication among the relevant social groups, identifying revenue streams, and developing government support. Overall, the findings from the analysis were varied in terms of value, sustainability, and scalability. Some projects started out strong and were successful in terms of value, however were neither sustainable nor scalable, while other projects started out weak but were later rewarded through ongoing persistence. Due to the variance of results from the case study analysis, Madon et al. (2009) concluded that rather than assessing digital inclusion projects solely on impact, additional assessment models needed to be developed to further expand on the ideas of sustainability and scalability in order to more accurately evaluate the success of digital inclusion projects in developing countries.

Warschauer (2004) conducted a similar analysis of additional case studies and found that multiple researchers and theorists who have investigated concepts surrounding the issue of digital inclusion have broken down the resources necessary for promoting social inclusion to include physical resources, digital resources, human resources, and social resources. The four types of resources must work in conjunction with each other in order to promote social development and inclusion, otherwise underdevelopment and exclusion might occur. Each of the four resources serves a dual purpose in that they contribute to the effective use of ICTs and they are the result of effective use of ICTs. While Warschauer (2004) was able to explain the connection between the four resources and their impact on social inclusion, no recommendation was identified for measuring project success. A more quantifiable method of measurement was identified by Alameu (2013) who suggested that digital inclusion entails more than a community being connected, 
disconnected, included or excluded; rather it involves addressing four key components: digital equity, digital excellence, digital opportunity, and digital empowerment.

Unlike the three crucial factors, the four key components involve a progression of levels within a hierarchical organizational structure. The base standard of the hierarchy, digital equity, consists of providing a reliable technical infrastructure upon which the digital inclusion project can be built (Gorski, 2009). Digital excellence, the second level of the progression, focuses on the promotion of digital awareness by developing an understanding of the technology and providing basic IT skills training to other citizens (Ware, Hartman, Roldan, Gebauer, \& Roldan, 1997). The third level, digital opportunity, builds upon the solid foundation afforded by digital equity and excellence by providing ICT access and the ability to influence the design of the technology (Maiken, 2006). Digital empowerment, the fourth level, involves the transference of skills obtained by both individuals and entire societies from mere consumers of basic technologies to digital innovators (Kanter, 1977). Together, the four key components represent community involvement in the planning, implementation, and evaluation of DIPs.

While digital equity, excellence, and opportunity are crucial, the level of success of digital inclusion projects revolves around digital empowerment. Makinen (2006) suggested merely providing physical access to ICTs is not sufficient enough and that the focus must be placed on addressing gaps in opportunity by empowering citizens to use technology to "participate more fully and equitably in society" (p. 352). Kanter (1977) developed the empowerment theory which suggests that when citizens to do not have access to resources, information, support, and opportunity they tend to feel disconnected and excluded from society. Empowerment is also an essential piece of the evaluation process. Fetterman and Wandersman (2005) described the concept of empowerment evaluation in which the community controls all aspects of the assessment process including speed and direction and the evaluator serves as a coach, facilitator, and mentor. Fetterman (2012) later suggested empowerment evaluation is designed to increase the probability of achieving program success by providing citizens with the tools for assessing the planning, implementation, and selfevaluation while involving assessment as part of the planning process. The three crucial factors (value, sustainability, and scalability) (Madon et al., 2009) and the four key components (digital equity, digital excellence, digital opportunity, and digital empowerment) (Alamelu, 2013) both entail aspects associated with empowerment theory and empowerment evaluation.

\section{Digital Inclusion Project Analysis}

The next segment of this paper includes an in-depth analysis of two different case studies that involved digital inclusion projects: the Siyabuswa Project and the Information Age Town Project. According to Johansson (2003), case study methodology involves evaluating a series of methods and tools that have been applied to a case to address a common problem from different angles, and Kitchenham, Pickard, and Pfleeger (1995) described how the methodology better ensures the processes being applied are producing the desired results. Based on the case study methodology, the two cases chosen for this analysis were selected because of the different approaches and process that were used to address the same common problem of digital inclusion in developing countries. After a brief introduction, each case study will be evaluated based on three crucial factors and four key components previously discussed. The results of the analysis will provide a more comprehensive understanding of how to better plan for and more effectively measure the success of future digital inclusion projects. 


\section{The Siyabuswa Educational Improvement and Development Trust Project}

One particular case study that has been conducted to assess the scalability of a digital inclusion project involves the small rural town of Siyabuswa located about $130 \mathrm{~km}$ outside of Pretoria in the Mpumalanga province of South Africa. The Siyabuswa Educational Improvement and Development Trust (SEIDET) was a project initiated by local community members to provide supplementary education to an area where less than $2 \%$ of young non-caucasians held college diplomas and less than $0.2 \%$ held university degrees (Phahlamohlaka \& Friend, 2004). Initially, SEIDET was developed when Jackie Phahlamohlaka, a Siyabuswa native and graduate school student, was challenged by community members to create a secondary education program aimed at improving mathematics and science opportunities, however SEIDET eventually expanded to include ICTbased interventions (Madon et al., 2009).

SEIDET was founded in 1992 and began as a non-governmental project designed to provide supplementary education to young people in a rural town that had witnessed substantial educational disadvantage over several years (Phahlamohlaka \& Friend, 2004). Eventually, in 1998, the program expanded when SEIDET teamed up with a private company to establish a 27 computer facility within the Siyabuswa community to provide secondary school teachers with a way to meet their computer literacy course requirements (Madon et al., 2009). The computer labs were also used to provide additional computer literacy courses to Siyabuswa citizens when SEIDET students were not attending classes. This part of the plan was an extra piece outside of SEIDET and the original Trust. In the beginning, the computer courses were offered to teachers through the University of Pretoria via satellite, however eventually SEIDET began sending teachers to Siyabuswa to provide face-to-face training. After a period, the Siyabuswa community was able to break off independently to sustain the computer literacy course without the financial or academic assistance of the Pretoria-based private training company (Alamelu, 2013).

From the beginning, the SEIDET project was built around voluntary tutors providing supplementary education to a multitude of subjects including ICT integration and commerce while promoting a high level of community involvement in community learning through relationships formed between tertiary institutions and the private sector (Phahlamohlaka \& Friend, 2004). In addition to the subject matter taught, the program also included career guidance and work placement for students. Over time, through continued support in the form of time and monetary resources, the local community coordinated efforts to provide similar ICT interventions to Siyabuswa citizens outside of the SEIDET program. Siyabuswa community members embraced the digital inclusion concept as they took command of the training facility and continued to ensure quality educational services were provided to a broad range of community members. Several graduates from the program found employment in ICT fields, and some were even able to use their newly acquired skills to start up new businesses (Madon et al., 2009).

The lessons learned from the Siyabuswa Project were scalable, as indicated by the fact that they paved the way for similar projects in nearby KwaMhlanga and Vaalbank, where two additional facilities were established in 1999 and 2000 (Madon et al., 2009). Shortly after the SEIDET facility expanded to include the two new sites, Mpumalanga leaders began discussing plans for a much larger roll-out of similar facilities in other rural areas of the region. The expansion of the program to additional sites became known as the Sustainable Development Initiative (SDI) (Phahlamohlaka, Dlamini, Mnisi, Mashiane, \& Malinga, 2014). SDI targeted other rural communities within the Mpumalanga region to serve as ICT development hubs similar to the SEIDET facility in Siyabuswa. Again, several researchers from the Siyabuswa Project teamed up with the private training company that assisted with the initial development of SEIDET to strategically and financially support further expansion of the original SEIDET facility. Four distinct phases were identified during the planning process: 1) identifying quality candidates to become trainers, 
2) training the candidates, 3) identifying suitable rural communities within Mpumalanga, and 4) empowering the communities through the establishment of local computer labs and active trainers (Madon et al., 2009).

SEIDET brought about a community response that far exceeded the expectations of project developers in a large part because the need for the program was widely perceived by local citizens in Siyabuswa and the two satellite communities of KwaMhlanga and Vaalbank (Phahlamohlaka et al., 2014). The SEIDET programs' success was a result of program developers empowering citizens from within the local communities to serve as volunteer tutors and designing a community-based evaluation system. The Strategic Choice Approach (SCA), the planning process that involves a participatory approach, was one of the driving forces behind the success of the SEIDET project (Phahlamohlaka, 2004). Developed as a way to address project planning in real-time under constantly changing conditions and actions, the approach involves maintaining a balance between four modes of decision making activity which include shaping, designing, comparing, and choosing (Friend \& Hickling, 1997).

The SCA's four-fold approach addresses two of the three crucial factors for planning digital inclusion project (value and sustainability), as well as all four key components (digital equity, excellence, opportunity, and empowerment). In a workshop which involved all the main SEIDET decision-makers, voluntary tutors from all three centers, plus the Executive Committee, worked to understand the SCA concept and how to effectively implement the approach in an effort to continually improve the SEIDET project (Phahlamohlaka, 2004). That provided an opportunity for equality in representation from a variety of community members, excellence through increased awareness of changes in the program, the opportunity to influence the design of the program, and empowering citizens to participate more fully and equitably within society. Simultaneously, while the SCA approach addressed the four key components, it involved a continued effort to increase the value and sustainability of the program through an annual planning process in which various committees and divisions collaborative developed new plans for moving the project forward (Phahlamohlaka, 2004). According to Alamelu (2013), a community must be "actively engaged in the creation of socio-technical systems" (p. 229) in order for a society to be considered digitally inclusive. Based on the three crucial factors, four key components, empowerment theory, and Dr. Alamelu's definition of digitally inclusive societies, the SEIDET project demonstrated success in addressing the digital divide through digital inclusion projects.

\section{An Information Age Town}

A national telecommunications company hosted a national competition in 1997 to transform a rural town in western Ireland into an Information Age Town (IAT). The project was developed to increase Ireland's progress towards being classified as an Information Society by introducing an integrated ICT infrastructure within an urban district to assess the social, educational, and economic impact on the community (McQuillan, 2002). Eircom, the telecommunications company that sponsored the contest, expressly stated two goals for the project: to see how local members of a rural Irish community would react to being saturated with $21^{\text {st }}$ century communications technology and to promote the use of new technologies and applications among local members of the commonwealth (McInerney, 2005). One of the prerequisites that were required for contest participation involved local community members collaborating to provide a detailed written vision of what an Information Age Town might look and how a given community might become one. The winning idea earned the town 15 million Irish pounds (about \$22 million U.S. dollars USD) to put towards implementation. Three additional prizes of 1 million Irish pounds (about $\$ 1.5$ million U.S. dollars USD) were awarded to the runner-ups (McQuillan, 2000). Although three additional towns were awarded runner-up prizes as part of the initial IAT contest, Warschauer (2004) ap- 
pears to have published the only literature on the results on the runners-up, so they will not be discussed in this paper.

Ennis, a small remote town of 18,000 people in western Ireland, was selected as the grand prize winner. At the time of the contest, Ennis had virtually no computers in its school(s), and because few teachers had ever personally used a computer there was much skepticism about technology actually being able to transform traditional teaching and learning practices (McInerney, 2005). The Task Force comprised of 11 men and five women representing the business, community, education, and public service sectors was credited with developing a winning proposal (McQuillan 2002). The winning proposal requested an Internet-ready computer and smart cards, pre-paid debit cards designed to create a cashless society for every local family, and an ISDN line, website, and smart-card readers for every business (Warschauer, 2004). One specific example Warschauer provided, in regards to how the smart cards and the smart card readers were supposed to be used to transform the local community into a cashless society, involved the unemployed using their new networked home computers to process unemployment payments rather than having to physically go to the unemployment office weekly.

Once the winner of the IAT contest had been identified, the Ennis community instantly began to develop and implement plan to transform the town from a digital ghost town into a digitally inclusive town infused with computers, software, network technology, and training designed to promote computer literacy among all town residents (McInerney, 2005). The project team, which was supported by voluntary Task Force members, expanded to include local advisory groups, community advocates, and additional groups from the community, business, and education sectors (McInerney, 2003). Even though the initial contest proposal included in essence the concept of what an IAT might include, it took the task force members about six months to develop a strategic plan for the project. The program included two key initiatives, which involved developing a robust ICT infrastructure within the entire town and investing in education and training in schools and throughout the local community (McQuillan, 2002).

Ennis consisted of a busy market center with good schools at the time of the contest, and many households did not have working phone lines, which were required to provide Internet access. So, the first step towards improving the town's network capabilities was to supply each house with Internet access, which involved the project managers having to provide phone connections to about six hundred families who had previously done without (McInerney, 2003). Once the network infrastructure was in place, the next step was to provide every home with a computer and to connect all home computers to the grid (Warschauer, 2004).

Education became a big focus associated with the IAT project once the implementation process began as witnessed by over 1.9 million dollars in prize money being dedicated for instructional purposes (McQuillan, 2000). Schools were not prepared in terms of space and training to handle the influx of all the new computers, monitors, and peripherals provided to them through the IAT project. Adequate space had to be identified within each school building, new furniture had to be added to hold the computers, teachers required computer training, and lessons had to be reconfigured in order to effectively integrate technology into the curriculum (McInerney, 2003). Once the technology was finally in place, many teachers found the challenge of determining how to take advantage of the technology best to be almost more taxing than actually physically obtaining the equipment (McInnerney, 2005).

Research on the IAT project is limited, and measurements of success vary between researchers. McQuillan (2002) reported an overall positive reaction from the people of Ennis, with $90 \%$ of citizens considering the project to be a good idea and $83 \%$ believing it provided Ennis with an advantage over other towns. In a multi-method study that began in 2001, McInerney (2005) published similar findings in terms of the IAT program having a positive effect on the Ennis educa- 
tion system in terms of instructional technology integration. Through multiple in-person interviews conducted with Ennis teachers, McInerney (2005) found that while many teachers had been extremely apprehensive about computers when the IAT was first initiated in 1997, by 2003, many were communicating regularly by email and were comfortable with the software. Contradictory to the findings of McQuillan (2002) and McInerney (2005), Warschauer (2004) reported the opposite results by stating that the IAT program actually disrupted the social system of local citizens causing resentment and frustration towards the technology resulting in several home machines being sold on the black market.

On the surface, it appears as if the town of Ennis successfully moved through the digital equity and digital excellence levels of progression according to the four key components for successful digital inclusion projects (McQuillan, 2002). Digital equity was specifically addressed on multiple levels when a networked computer was installed in each family home and the same opportunity was provided to each of the schools within the Ennis community (McInerney, 2005; McQuillan, 2002; Warschauer, 2004). Outside of equity and excellence, it appears that digital opportunity and empowerment were primarily achieved by teachers within the Ennis educational system according to a detailed study published by McInerney (2005). The published research about the IAT project does not appear to demonstrate the impact the IAT had on additional Ennis community members or businesses in relation to digital opportunity and empowerment. In terms of the three crucial factors, the IAT project explicitly addressed value and sustainability as they were part of the initial application process that resulted in the Ennis community being awarded the IAT prize money (McInerney, 2005). Scalability was not demonstrated as part of the IAT project. The prize money was only awarded to four specific towns, and no research has been published which demonstrates a transference of the projects developed within those four towns to other outside communities.

\section{Discussion}

The next segment of this paper will include an in-depth analysis of two different case studies that involved digital inclusion projects: the Siyabuswa Project and the Information Age Town Project. According to Johansson (2003), case study methodology involves evaluating a series of methods and tools that have been applied to a case to address a common problem from different angles, and to better ensure the processes being applied are producing the desired results (Kitchenham et al., 1995). Based on the case study methodology, the two cases chosen for this analysis were selected because of the different approaches and process that were used to address the same common problem of digital inclusion in developing countries. After a brief introduction, each case study will be evaluated based on three crucial factors and four key components previously discussed. The results of the analysis will provide a more comprehensive understanding of how to better plan for and more effectively measure the success of future digital inclusion projects.

This study provided significant findings relating to the importance of involving a variety of stakeholders from different areas within each community in planning for, implementing, and evaluating of DIPs. DIPs were introduced as a strategy to assist with addressing the digital divide, which continues to affect people from diverse backgrounds, varying educational levels, and communities that stretch around the globe.

The two community projects used in this study where chosen based on the differences in their status in terms of the town being considered developed or developing. Siyawbsa, a town where a very small fraction of the people living in the community held college diplomas or university degrees (Phahlamohlaka \& Friend, 2004), was classified as developing. No access to ICTs was available until the SEIDET project partnered with a private company to bring a 27 networked computer lab to the area (Madon et al., 2009). Ennis was considered to be more developed as they had already developed a strong education system and the town was considered to be a business 
hub for the region. Like Siyawbsa, Ennis too did not have access to ICTs until the IAT project began (McInerney, 2005). The two DIPs addressed the digital divide differently in each of their respective communities. Siyabwsa put a centralized computer lab in the center of the town to serve as an educational hub for all the local citizens, which assisted with bringing the community together. Ennis placed networked computers in each family home and then outfitted the schools with 1.9 million USD of technology.

\begin{tabular}{|l|l|l|}
\hline \multicolumn{3}{|c|}{$\begin{array}{c}\text { Table 1: Determinations of Success for the Siyabuswa and Information Age Town } \\
\text { Projects According to the Three-Crucial Factors and Four-Key Components }\end{array}$} \\
\hline & SIYABUSWA PROJECT & INFORMATION AGE TOWN \\
\hline Factor 1- Value & Yes & Yes \\
\hline Factor 2- Sustainability & Yes & Yes \\
\hline Factor3- Scalability & Yes & No \\
\hline Component 1- Equity & Yes & Yes \\
\hline Component 2- Excellence & Yes & Yes \\
\hline $\begin{array}{l}\text { Component 3- Opportunity } \\
\text { Component 4- Empowerment }\end{array}$ & Yes & Teachers Only ${ }^{\text {a }}$ \\
\hline $\begin{array}{l}\text { Note. } \text {. A review of the case study did not reveal information on the impact in terms of the } \\
\text { community as a whole. }\end{array}$ & \\
\hline
\end{tabular}

Table 1 provides details on how successful each of the two digital inclusion projects were in terms of the three crucial factors and four key components outlined in this study. Digital inclusion projects in general were shown to have some level of positive impact on addressing the digital divide and access to ICTs in Ennis, Ireland and Siyabuswa, South Africa. The SEIDET project demonstrated how focusing on value and sustainability, two of the three crucial factors, throughout the planning, implementation, and evaluation process eventually led to scalability of the project when it was replicated in two additional South African communities. The Siyabuswa citizens experienced digitally equality as the community found additional ways to use the computer lab when teacher training was not in session. They experienced digital excellence and opportunity by finding ways to expand the capabilities of the lab, and eventually empowerment was achieved when community members reinvested in the training program and many started their own businesses. The Ennis citizens placed their focus on improving ICT access in every home and in every school to increase the value and sustainability of DIPs in their community. The IAT project originally brought fear and anxiety to the teachers in Ennis, however after an intense focus on technology integration training, they quickly moved from being simply digital equals to being digitally excellent and opportunistic before eventually demonstrating a level of digital empowerment among area teachers. Unfortunately, the IAT project research did not demonstrate how the newly transformed education system impacted the local community in terms of addressing the digital divide, nor did the research explain anything that would indicate scalability for this project.

\section{Conclusion}

Community involvement in the planning, implementation, and evaluation stage was determined to be essential as witnessed in both DIPs. The evaluation process must occur on a regular basis in order to ensure a higher level of success and to continually narrow the gap associated with the digital divide. Addressing the digital divide involves more than providing communities with in- 
creased access to ICTs, a major focus has to be placed on education and training both with the consumers and the instructors using the technology. Finally, the DIP must empower the community to continuously be involved with the project and find way to transfer the skills obtained by both individuals and entire societies from simple consumers of basic technologies to digital innovators (Kanter, 1977). Together, as demonstrated in the two projects presented in this study, these concepts are crucial focal points for future digital inclusion projects.

\section{References}

Alamelu, K. (2013). Digital inclusion- A conceptual framework. International Journal of Advanced Research in Management and Social Sciences, 2(12), 228-248.

Costello, J. (2000). Education: The fuel for tech's Golden Age. Electronic Business, 26(11), 20-21.

Dangwal, R., \& Kapur, P. (2009). Learning through teaching: Peer-mediated instruction in minimally invasive education. British Journal of Educational Technology, 40(1), 5-22.

Fetterman, D. M., \& Wandersman, A. (Eds.). (2005). Empowerment evaluation principles in practice. Guilford Press.

Fetterman, D. (2012). Empowerment evaluation in the digital villages: Hewlett-Packard's 15 million race toward social justice. Palo Alto: Stanford University Press.

Friend, J. K., \& Hickling, A. (1997). Planning under pressure: The strategic choice approach. Butterworth-Heinemann, Oxford.

Gorski, P. (2009). Insisting on digital equity: Reframing the dominant discourse on multicultural education and technology. Urban Education, 44, 348-369.

Harris, R.W., Kumar, A., \& Balaji, V. (2003). Sustainable telecentres? Two cases from India. In S. Krishna $\&$ S. Madon (Eds.), The digital challenge: Information technology in the development context (pp. 124-135). Aldershot: Ashgate Publishing.

Johansson, R. (2003). Cast study methodology. In the International Conference on Methodologies in Housing Research, Stockholm.

Kanter, R. M. (1977). Men and women in the corporation. New York, NY Basic Books.

Kitchenham, B., Pickard, L., \& Pfleeger, S.L. (1995). Case studies for method and tool evaluation. IEEE software, 12(4), 52-62.

Kraemer, K. L., Dedrick, J., \& Sharma, P. (2009). One laptop per child: vision vs. reality. Communications of the ACM, 52(6), 66-73.

Madon, S., Reinhard, N., Roode, D., \& Walsham, G. (2009). Digital inclusion projects in developing countries: Processes of Institutionalization. Information Technology for Development, 15(2). 95-107. doi: 10.1002/itdj.20108

Maiken, M. (2006). Digital empowerment as a process for enhancing citizens' participation. E-learning, 3(3), 381-395.

McInerney, C. (2003). Wired Ennis: Learning and technology in an information age town. Information Technology Education and Society Albert Park, 4(2), 9-34.

McInerney, C. (2005). Educational inquiry and creativity: Developing digital resources in Ireland's Informational Age Town. Library Trends, 54(2), 266-285. doi:10.1353/lib.2006.0019

McQuillan, H. (2000). A connected community: Ennis Information Age Town [Report]. Ennis: Eircom.

McQuillan, H. (2002). Ennis Information Age Town: Virtually rooted in reality. Digital Cities II: Computational and Sociological Approaches, 139-151. Springer Berlin Heidelberg. 
Mitra, S., Dangwal, R., Chatterjee, S., Jha, S., Bisht, R. S., \& Kapur, P. (2005). Acquisition of computing literacy on shared public computers: Children and the "Hole in the Wall." Australasian Journal of Educational Technology, 21(3), 407-426.

Phahlamohlaka, J., Dlamini, Z., Mnisi, T., Mashiane, T., \& Malinga, L. (2014). Towards a smart community centre: SEIDET digital village. In ICT and society (pp. 107-121). Springer Berlin Heidelberg.

Phahlamohlaka, J., \& Friend, J. (2004). Community planning for rural education in South Africa. European Journal of Operational Research, 152(3), 684-695.

Sahay, S., \& Walsham, G. (2006). Scaling of health information systems in India: Challenges and approaches. Information Technology for Development, 12(3), 185-200.

Trauth, E. M., Howcroft, D., Butler, T., Fitzgerald, B., \& DeGross, J. I. (2006). Social inclusion: Societal and organizational implications for information system. New York: Springer.

Ware, J., Hartman, A., Roldan, N., Gebauer, J., \& Roldan, M. (1997). The search for digital excellence. McGraw-Hill, Inc.

Warschauer, M. (2004). Technology and social inclusion: Rethinking the digital divide. Boston, MA: MIT Press.

Wresch, W. (2009). Progress on the global digital divide: An ethical perspective on amartyasen's capabilities model. Ethics and Information Technology, 11(4), 255-263. doi: 10.1007/s10676-009-9205-y

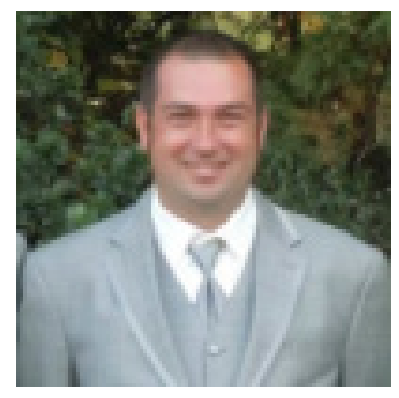

\section{Biography}

Chris Smith is a Doctorate in Education student in Educational Technology at Boise State University. He obtained a master's degree in Instructional Technology from Appalachian State University in 2009 and a bachelor's degree in Elementary Education from the University of Charleston in 2001. He currently serves as the Director of Distance Learning at Western Piedmont Community College and his research interests include: online professional development communities, support services for online students, and active learning experiences in online courses. 